University of Nebraska - Lincoln

DigitalCommons@University of Nebraska - Lincoln

\title{
Southeastern U.S. Vegetation Response to ENSO Events (1989-1999)
}

\author{
Albert J. Peters \\ University of Nebraska-Lincoln, apeters@calmit.unl.edu \\ Lei Ji \\ University of Nebraska-Lincoln \\ Elizabeth A. Walter-Shea \\ University of Nebraska - Lincoln, ewalter-shea1@unl.edu
}

Follow this and additional works at: https://digitalcommons.unl.edu/calmitpapers

Part of the Natural Resources Management and Policy Commons

\footnotetext{
Peters, Albert J.; Ji, Lei; and Walter-Shea, Elizabeth A., "Southeastern U.S. Vegetation Response to ENSO Events (1989-1999)" (2003). Center for Advanced Land Management Information Technologies-Publications. 2.

https://digitalcommons.unl.edu/calmitpapers/2
}

This Article is brought to you for free and open access by the CALMIT: Center for Advanced Land Management Information Technologies at DigitalCommons@University of Nebraska - Lincoln. It has been accepted for inclusion in Center for Advanced Land Management Information Technologies--Publications by an authorized administrator of DigitalCommons@University of Nebraska - Lincoln. 
Published in Climatic Change 60 (2003), pp. 175-188.

Copyright @ 2003 Kluwer Academic Publishers. Used by permission.

Submitted May 29, 2002; revised March 31, 2003.

Published as Paper No. 13698, Journal Series, Nebraska Agricultural Research Division.

\title{
Southeastern U.S. Vegetation Response to ENSO Events (1989-1999)
}

\author{
Albert J. Peters, ${ }^{1}$ Lei Ji, ${ }^{1}$ and Elizabeth Walter-Shea ${ }^{2}$ \\ 1. Center for Advanced Land Management Information Technologies, University of Nebraska- \\ Lincoln, 113 Nebraska Hall, Lincoln, NE 68588-0517, U.S.A. Email: apeters@calmit.unl.edu \\ 2. School of Natural Resource Sciences, University of Nebraska-Lincoln, \\ 303 Biochemistry Hall, Lincoln, NE 68583-0758, U.S.A.
}

\begin{abstract}
.
El Niño/Southern Oscillation (ENSO) is considered one of the most powerful forces driving anomalous global weather patterns. Large-scale seasonal precipitation and temperature changes influenced by ENSO have been examined in many areas of the world. The southeastern United States is one of the regions affected by ENSO events. In this study, remote sensing detection of vegetation response to ENSO phases is demonstrated with one-kilometer biweekly Normalized Difference Vegetation Index (NDVI) data (1989-1999) derived from the Advanced Very High Resolution Radiometer (AVHRR). The impacts of three ENSO phases, cold, warm and neutral, on vegetation were analyzed with a focus on two vegetation cover types, two seasons and two geographic regions within the southeastern U.S. Significant ENSO effects on vegetation were found in cropland and forest vegetation cover types based on image and statistical analysis of the NDVI data. The results indicate that vegetation condition was optimal during the ENSO neutral phase for both agricultural and natural vegetation.
\end{abstract}

\section{Introduction}

El Niño-Southern Oscillation (ENSO) is a coupled ocean-atmosphere phenomena in the tropical Pacific that is, after the seasons, the most powerful force driving global weather changes. Large-scale precipitation and temperature patterns influenced by ENSO have been examined in many areas of the world (Ropelewski and Halpert, 1986; Kiladis and Dias, 1989; Barnett et al., 1994; Adams et al., 1995; Barsugli et al., 1999; McCabe and Dettinger, 1999; Rajagopalan et al., 2000). The Southeast United States is no exception. For example, during warm events, winter precipitation is anomalously high, but temperatures are low due to increased cloud cover, while summers tend to be dry along the southeast coast (Ropelewski and Halpert, 1986; Adams et al., 1995). Impacts of ENSO on agriculture and crop production in the Southeast U.S. have been reported (Adams et al., 1995; Hansen et al., 1998). 
Satellite imagery provides high-spatial and -temporal resolution coverage, which can be used to efficiently evaluate global and regional vegetation condition. At present the Advanced Very High Resolution Radiometer (AVHRR) on board the National Oceanic and Atmospheric Administration's (NOAA's) polar-orbiting satellites is the instrument of choice for collecting 1-kilometer resolution imagery worldwide because there is more than 12 years of historical data (Batista et al., 1997). The Normalized Difference Vegetation Index (NDVI), a measure typically derived from AVHRR data, is calculated as:

$$
\left.\mathrm{NDVI}=\left(\rho_{\mathrm{NIR}}-\rho_{\mathrm{vis}}\right) / \rho_{\mathrm{NIR}}+\rho_{\mathrm{vis}}\right)
$$

where $\rho_{\mathrm{NIR}}$ is the reflectance in the near-infrared waveband and $\rho_{\mathrm{vis}}$ is the reflectance in the visible red waveband of the satellite radiometer (Justice et al., 1985). This ratio provides an indicator of vegetation condition, or vigor, such that the higher the NDVI value the greater the level of photosynthetic activity in the cover type (Sellers, 1985; Tucker et al., 1991: Bannari et al., 1995; Tucker and Sellers, 1996). Multitemporal NDVI derived from AVHRR data are useful for monitoring vegetation dynamics on regional and continental scales (Goward et al., 1985; Tucker et al., 1991, 1996; Eidenshink and Haas, 1992; Benedetti and Rossini, 1993; Unganai and Kogan, 1998; Moulin et al., 1998). Therefore, NDVI derived from AVHRR can be applied effectively to detect variations in vegetation condition induced by ENSO at global and continental scales.

Recent research has investigated the relationship between AVHRR-NDVI and ENSO indices in various regions of the world. For example, Eastman and Fulk (1993), and Anyamba and Eastman (1996) employed principal component analysis techniques for time series AVHRR-NDVI in Africa. They found that interannual NDVI variation was strongly related to three ENSO indices: atmospheric pressure patterns, Pacific sea-surface temperature and anomalous outgoing long-wave radiation. Significant reductions in NDVI values were associated with ENSO events in the Amazonian region of South America (Batista et al., 1997). Gutman et al. (2000) used AVHRR data to determine the signatures of ENSO impacts on the surface- atmosphere system over the Indonesian archipelago. Kogan (2000) examined the association between sea surface temperatures (SST) anomalies in the tropical pacific and a vegetation health index derived from AVHRR-NDVI for the entire world. Liu and Engrón Juárez (2001) constructed linear regression models for AVHRR-NDVI and ENSO indices and applied the models to predict ENSO-related drought onset in Brazil. Li and Kafatos (2000) found the interannual variation of vegetation estimated from AVHRR-NDVI is strongly related to ENSO indices in the United States. Mennis (2001) found a clearly recognizable relationship between ENSO events and interannual fluctuation in NDVI in the states of North and South Carolina, and Georgia in the southeastern U.S. Warm phase events were associated with a decline in vegetation vigor while the cold phases were associated with an increase.

So far, studies of ENSO impact in the southeastern U.S. have focused primarily on the response of climate (Ropelewski and Halpert, 1986; Rajagopalan et al., 2000; 
Goodman et al., 2000; Katz et al., 2003) and agricultural yield (Adams et al., 1995, 1999; Hansen et al., 1998). Investigations into the response of vegetation as viewed with satellite data have been reported recently (Kogan, 2000; Li and Kafatos, 2000; Mennis, 2001). Although Kogan (2000) and Li and Kafatos (2000) found ENSO impacts on land ecosystems in the southeastern U.S., their interests were focused on NDVI variation at global and continental scales. Mennis (2001) looked at the relationship between SST and NDVI, noting a negative correlation between SST anomalies and NDVI, in the states of North and South Carolina, and Georgia, but regional variability of NDVI in response to ENSO was not demonstrated. The objective of our study was to investigate changes in the AVHRR signal as an indicator of changes in vegetation condition, induced by ENSO in the southeastern U.S. as a whole and variation within the region as well, with fine spatial resolution imagery. Two cover types, two seasons and two geographic areas were compared and contrasted in order to explore ENSO impacts on vegetation.

\section{Material and Methods}

\subsection{DATA}

\subsubsection{Satellite Sensor Data}

Biweekly (14-day) Maximum Value Composite NDVI (1-km resolution) data (1989-1999) from the Earth Resources Observation System (EROS) Data Center, United States Geological Survey (USGS) were used in this study. The maximum value composite process retains the highest NDVI values during each 14-day period, producing images that are spatially continuous and relatively cloud-free, with temporal resolution sufficient for evaluating vegetation dynamics (Holben, 1986; Eidenshink, 1992). Data from September-December 1994 was not used due to failure of the AVHRR sensor.

\subsubsection{Seasonal Land Cover}

The Conterminous U.S. Land Cover Characteristics Data set (Loveland et al., 1991; Eidenshink, 1992), developed at EROS and the University of Nebraska-Lincoln (U.S.A.) was used to characterize land cover based on seasonal vegetation phenology. This land cover image was developed with multi-temporal AVHRR time-series from 1990. Post-classification refinement was accomplished using ancillary earth science data sets, including topography, climate, soils, and ecoregions. Land cover classes are defined at 1 kilometer. For our purposes, the original 159 classes were regrouped into seven cover types (Figure 1), and five were used for this analysis: cropland, mixed cropland/woodland and deciduous, coniferous and mixed forests. From these five classes, two broad classes were defined: cropland (cropland and mixed cropland/ woodland classes) and forest (deciduous, coniferous and mixed forest classes). Pixels classified as urban and built-up areas, wetlands, water bodies and "other" were removed from the analysis to reduce the impact of these cover types on those of interest. 

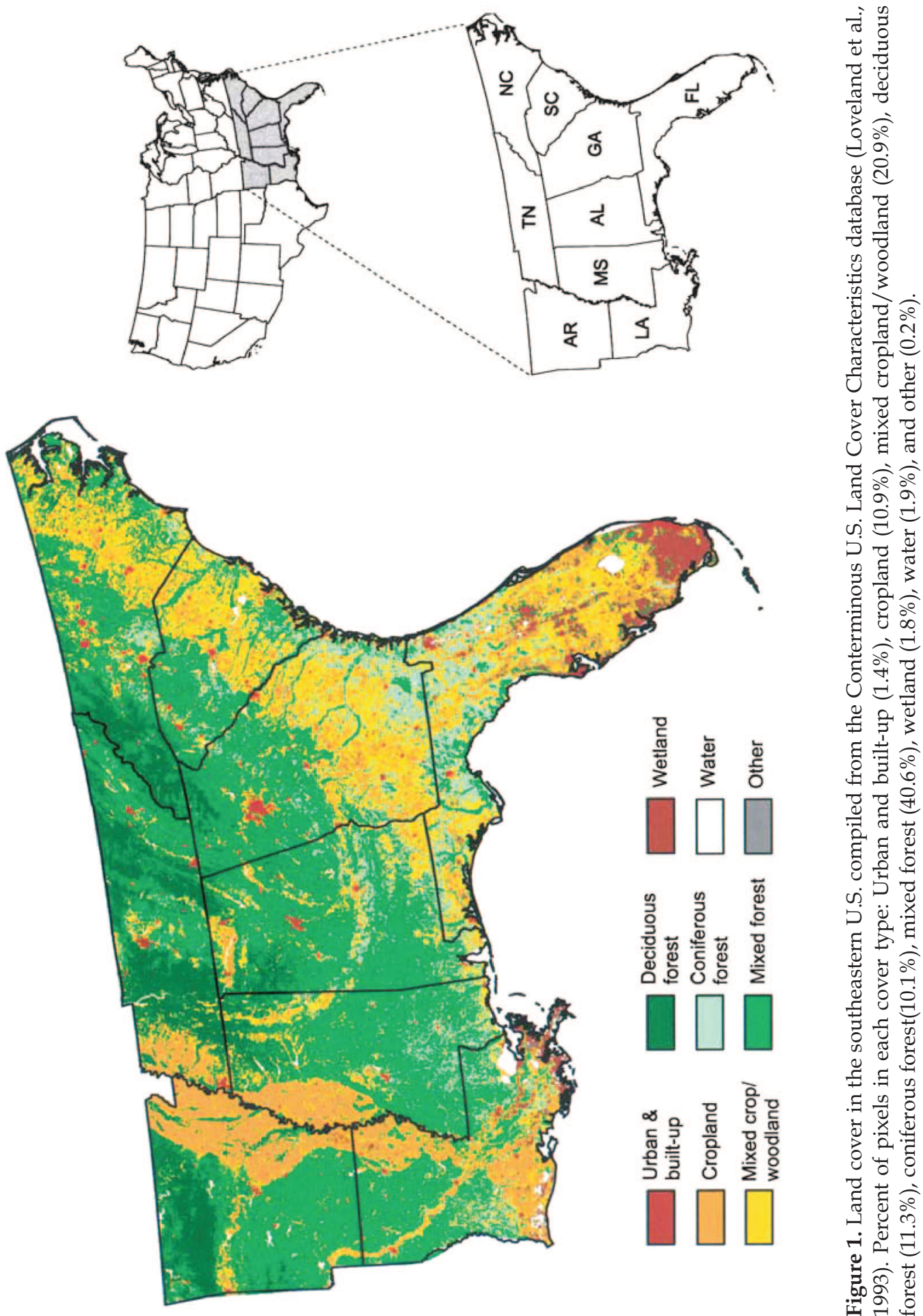


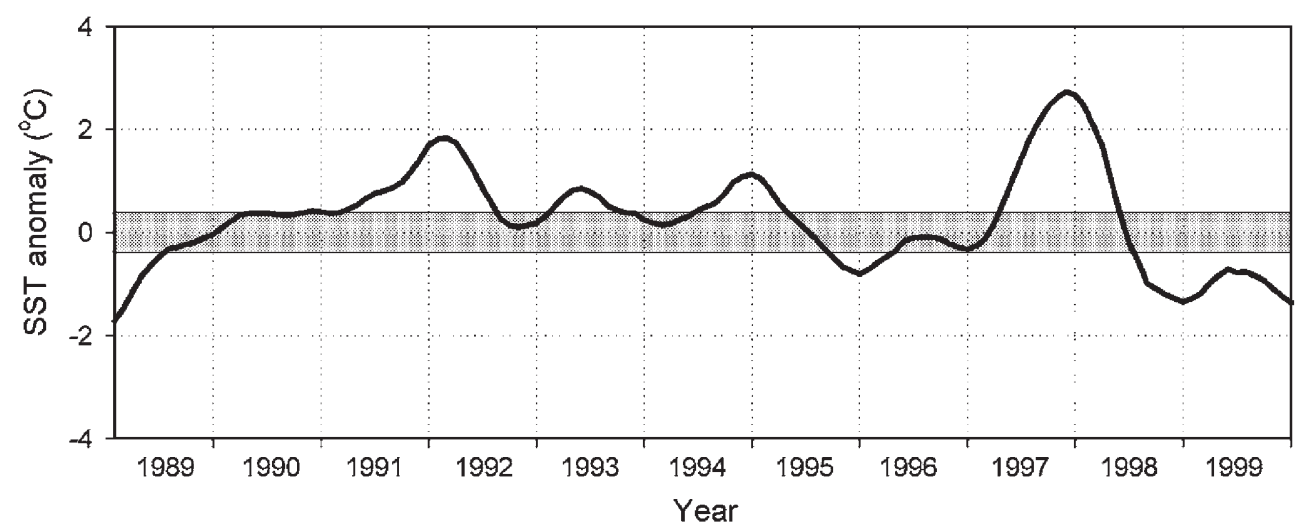

Figure 2. Time Series of SST (Niño 3.4) anomalies (1989-1999). The gray bar represents ENSO phase thresholds at $\pm 0.4{ }^{\circ} \mathrm{C}$.

\subsubsection{Sea Surface Temperature}

Sea Surface Temperatures (SSTs) in the equatorial Pacific Ocean were used to define ENSO events. By definition, El Niño occurs if 5-month running means of SST anomalies in the Niño 3.4 region $\left(120^{\circ} \mathrm{W}-170^{\circ} \mathrm{W}, 5^{\circ} \mathrm{S}-5^{\circ} \mathrm{N}\right)$ exceed $0.4^{\circ} \mathrm{C}$ for 6 months or more (Trenberth, 1997). SST anomalies were calculated by subtracting the monthly SST mean from the monthly SST time series. The monthly SST mean was derived from a base period of 1950-1979. Trenberth and Hoar (1996) stated that this base period was representative of sea-surface temperature conditions during this century, whereas the period after 1979 had been biased by warm events. SST data obtained from the Climate Prediction Center, NOAA/National Weather Service (http://www.cpc.noaa.gov/data/indices/index.html) were used to calculate the 1989-1999 monthly SSTs (Figure 2). Three ENSO phases were defined based upon the SST anomalies: warm and cold phases are defined as temperature anomalies above and below $\pm 0.4{ }^{\circ} \mathrm{C}$ respectively, while the neutral phase is defined when temperatures are within the range of $\pm 0.4^{\circ} \mathrm{C}$ (Figure 3).

\subsection{METHODS}

\subsubsection{Standardized Departure of NDVI}

Monthly NDVI images were created using a linear interpolation technique in order to match the SST time series. Standardized Departure of NDVI was used to permit viewing the spatial patterns of vegetation change during ENSO phases. This is defined as the difference between the mean NDVI during an ENSO phase and the mean NDVI of the study period (1989-1999), divided by the standard deviation of the time series. Standardized departure images were calculated as the average departure during the growing season (May-October) and winter (December-February) for each ENSO phase (1989-1999) so that trends for each ENSO phase could be observed. Standardized departure could thus be negative (indicating a decrease in vegetation 


\begin{tabular}{|c|c|c|c|c|c|c|c|c|c|c|c|c|}
\hline & Jan & Feb & Mar & Apr & May & Jun & Jul & Aug & Sep & Oct & Nov & Dec \\
\hline 1989 & & & & & & & & & & & & \\
\hline 1990 & & 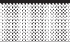 & & & & & & & & 7 & & \\
\hline 1991 & & 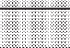 & & & & & & & & & & \\
\hline 1992 & & & & & & & & 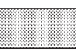 & In & 18 & & \\
\hline 1993 & & & & & & & & & & 3 & 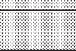 & \\
\hline 1994 & : & 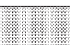 & 8 & & & & & & & & & \\
\hline 1995 & & & & & & & & & & & & \\
\hline 1996 & & & & & & 8 & 8 & 8 & & 8 & & \\
\hline 1997 & & & & & & & & & & & & \\
\hline 1998 & & & & & & & & & & & & \\
\hline 1999 & & & & & & & & & & & & \\
\hline
\end{tabular}

\section{Cold phase $\square$ Neutral phase $\square$ Warm phase}

Figure 3. Cold, neutral, and warm ENSO phases as defined by SSTs in the Niño 3.4 Region.

vigor), positive (indicating an increase) or close to zero (little or no change). Trends in NDVI departure were compared to climate observations from the Weekly Weather and Crop Bulletin (NOAA).

\subsubsection{Regional Significance of ENSO Phases in Cropland and Forests}

To geographically isolate ENSO impacts in the SE U.S., two subregions were selected for analysis, the Gulf Coast and Interior; an "other" class included remaining areas (Figure 4). Boundaries of these areas are defined by Climate Divisions. Timeseries of cropland-and forest-NDVI means were retrieved for each biweekly period from 1989-1999. The mean and standard deviation of NDVI by ENSO phase and subregion were calculated for each Climate Division. Analysis of variance (ANOVA) was used to test the significance of ENSO phase effects on regional NDVI. In a two-way ANOVA model (Kuehl, 2000), ENSO phase and regional effects were considered as factors affecting vegetation condition. The linear ANOVA model for the two-way factorial design is given by:

$$
\mathrm{NDVI}_{i j k}=\mu+\mathrm{ENSO}_{i}+\text { subregion }_{j}+\left(\text { ENSO } \times \text { subregion }_{i j}+\varepsilon_{i j k},\right.
$$

where $\mu$ is the overall mean NDVI for all ENSO phases for the entire southeastern U.S., $\mathrm{ENSO}_{i}$ is the effect of the $i$ th ENSO phase (cold, warm, neutral), subregion ${ }_{j}$ is the

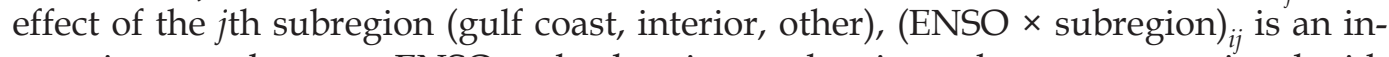
teraction term between ENSO and subregion, and $\varepsilon_{i j k}$ is random error associated with the $i$ th ENSO and $j$ th subregion.

Spatial autocorrelation of NDVI likely exists between climate divisions since there are obvious spatial gradients and heterogeneity. Spatial autocorrelation violates the basic assumption of independent observations in a conventional ANOVA and can result in erroneous conclusions about the effect of the factors (Legendre, 1993; Griffith, 1996). Thus, an adjustment for spatial autocorrelation was applied by integrating this 


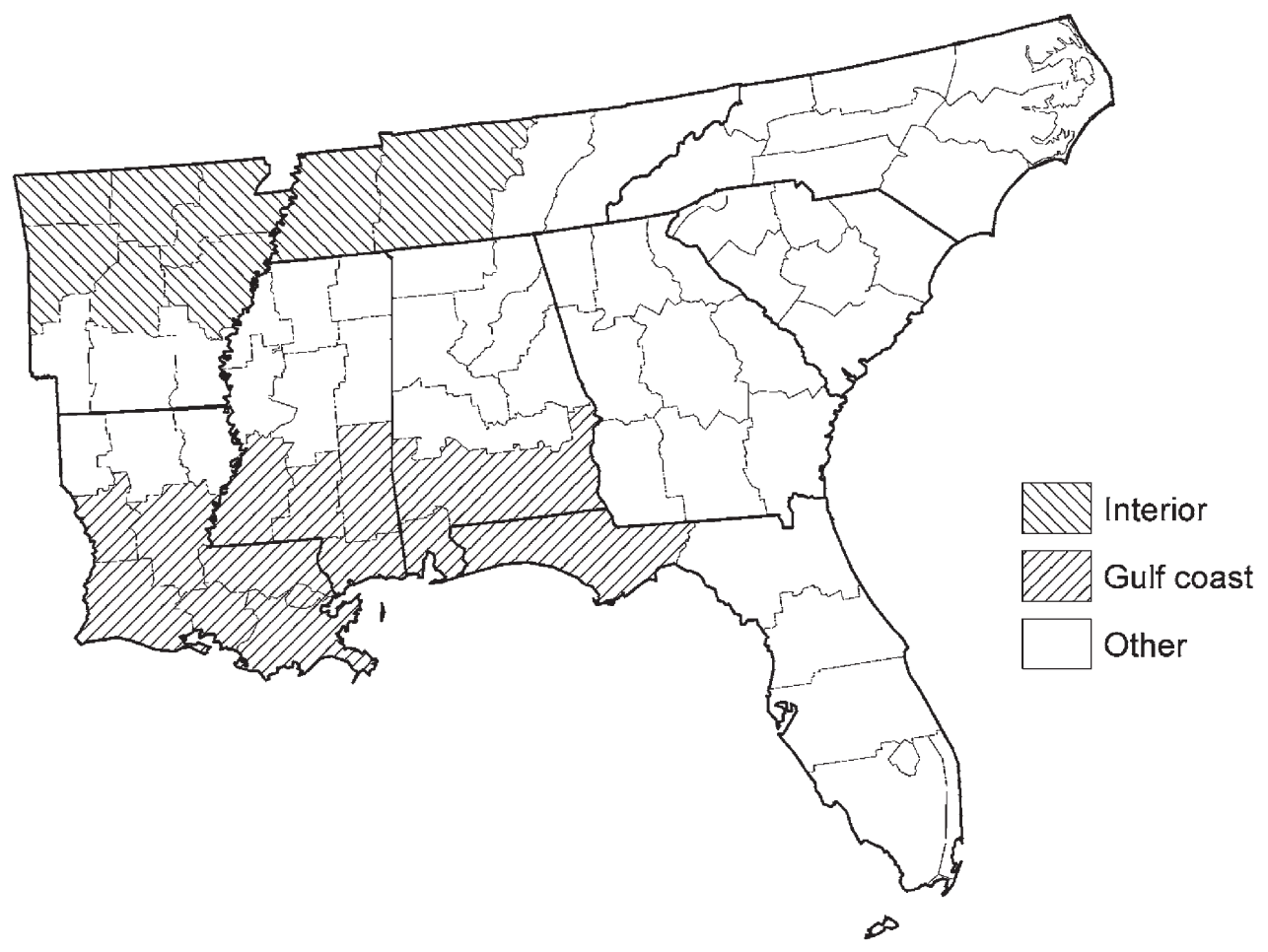

Figure 4. Interior, Gulf Coastal and other subregions of the Southeastern U.S. with boundaries defined by the Climate Divisions.

variability into the ANOVA model with the mixed model technique (Littell et al., 1996). The least square means were then adjusted and new NDVI values were compared by region, season and ENSO phase. The ANOVA was performed for each combination of the two cover types and two seasons, i.e., cropland/growing season, forest/growing season, cropland/winter and forest winter. The ENSO, subregion and their interaction effects were tested with the ANOVA.

\section{Results and Discussion}

\subsection{OVERALL VIEW OF NDVI RESPONSE TO ENSO PHASES}

A comparison of SST in the Niño 3.4 region (Figures 2 and 3) and NDVI standardized departure images in the southeastern U.S. (Figure 5) depict the trends and spatial variation in vegetation response to ENSO phases. The SST warm phases tend to be characterized by summer droughts, resulting in lower than average NDVI (Figure 5C). The years 1991-94 represent an SST warm phase interrupted by brief periods of SST neutral conditions, and were characterized by reduced crop yields and dry pastures during the summer in most areas and extreme winter moisture and increased 
NDVI along the Gulf Coast and Florida. In fact, 1993 was the driest and the second hottest summer of the 20th century in the Southeast. The year 1997 was characterized by drought aggravated by spells of heat that hurt crops in parts of the Southeast. The finding of reduced vegetation condition during the warm phase is corroborated by the work of Mennis (2001) who concluded that the vegetation vigor of all land cover classes declined during the warm phase.

Cold SST anomalies tended to be characterized by pockets of drought as indicated by poor vegetation condition (Figure 5A). Lingering dryness in 1989 in the aftermath of the severe 1988 drought was evident; however, timely summer rains in 1989 returned corn and soybean crops to their near long-term yield trend. In 1995 a marked change in circulation patterns resulting from the decline of the long warm phase, brought severe heat waves through September. Diminishing wet and stormy conditions in the early part of 1998 coincided with declining sea surface temperatures and resulted in improved growing conditions. Drought occurred in the summer but was eased somewhat by scattered thunderstorms. However, winter dryness continued into 1999 through the summer, causing considerable losses for agriculture as growing conditions deteriorated during the cold SST conditions that had not seen since 1988/1989. The cold phase growing season exhibited a complex spatial pattern with below average vegetation conditions throughout Florida, along the Mississippi River floodplain and the North Carolina coast while above average conditions were observed along the Gulf Coast centered in Mississippi and Louisiana (Figure 5A). The Mississippi floodplain is one of the most densely cropped sections of the study area (Figure 1), where rice, soybeans, cotton and winter wheat are grown. The negative impact of the cold phase vs. warm phase weather on cropland in this area can be seen in Figures 5A,C.

Average to above average growing-season NDVI occurred during the SST neutral phases (Figure 5B). These conditions occurred in late 1989 and early 1990 and in brief periods of 1992, 1994, 1996 and 1998 (Figures 2 and 3). Late 1989 was characterized by wet conditions which broke the drought and resulted in improved growing conditions, with corn and soybean yields back to near normal. Higher crop yields in the Mississippi valley in neutral as compared to cold phase years have been confirmed (http://www.usda.gov/nass/graphics). Of the three SST anomalies, the neutral phase was optimum for vegetation during the growing season. This differs from previous results found in correlation analyses of SST and NDVI relationships (Kogan, 2000; Mennis, 2001; Liu and Juárez, 2001), due primarily to the fact that these relationships are not linear. In other words, both high and low SST anomalies induce less favorable climate for vegetation with the warm phase having the greater negative effect.

Winter growing conditions also showed a considerable amount of variation between ENSO phases. During neutral SST conditions (Figure 5E), NDVI was fairly close to average throughout the region with the exception of the Gulf Coast and Florida. Cold phase NDVI (Figure 5D) was generally above average which is consistent with warmer and drier winter weather (Ropelewski and Halpert, 1986; Kiladis 

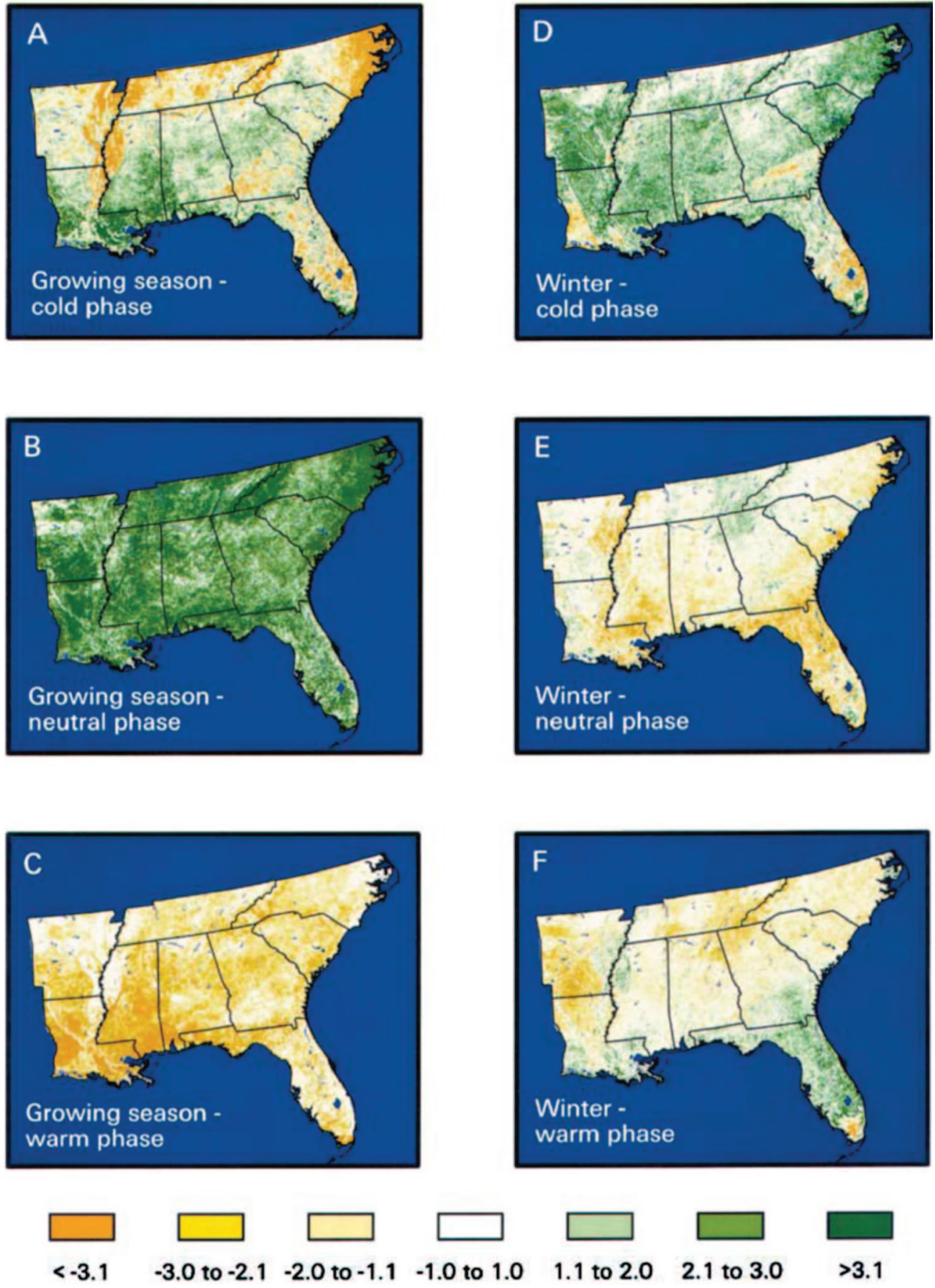

Figure 5. Standardized Departure of NDVI by ENSO phases: A: Growing season - cold; B: Growing season - neutral; C: Growing season - warm; D: Winter - cold; E: Winter - neutral; F: Winter - warm. 

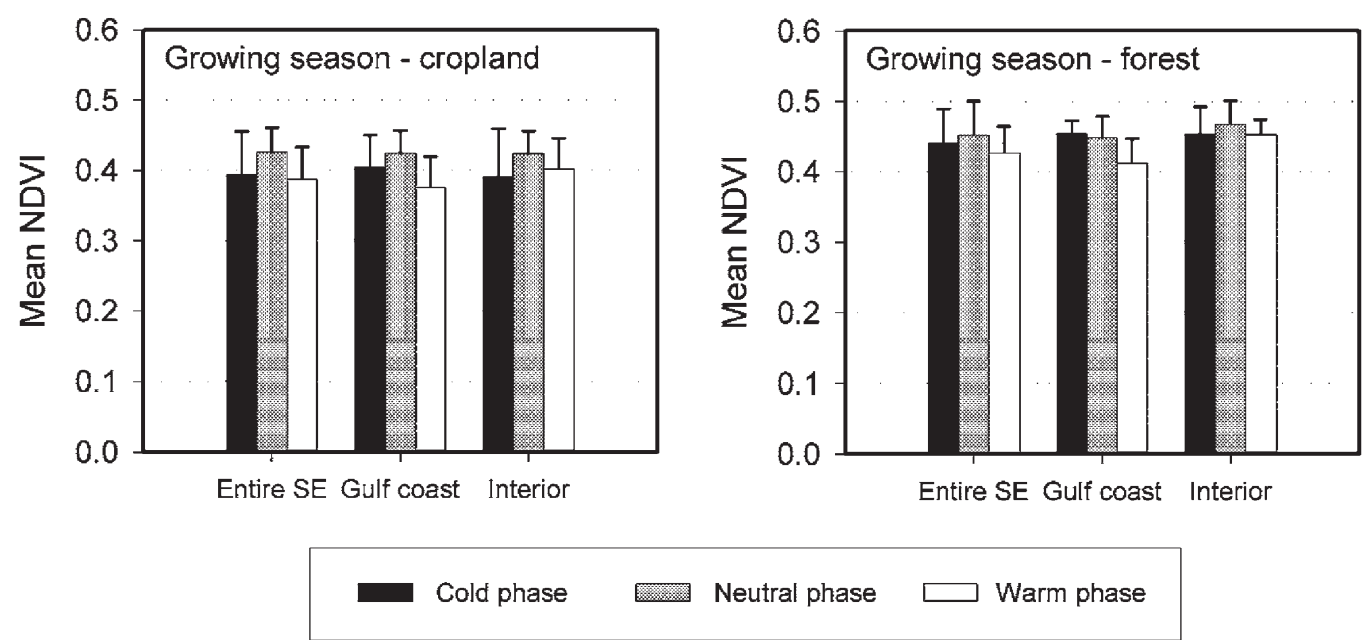

Figure 6. Mean NDVI for the three ENSO phases. Comparisons are made for cropland vs. forest and gulf coast vs. interior regions during the growing season from May thru October. The horizontal bars indicate one standard deviation.

and Diaz, 1989). Warm-phase winter vegetation was average to below average except along the Gulf Coast and most of Florida (Figure 5F), which is consistent with more sun and drier weather in this region (Ropelewski and Halpert, 1986; Kiladis and Diaz, 1989). Warm phase winters are characterized by wet and mild weather, resulting in lower than average NDVI, except along the Gulf coast (Figures 5C,F).

\subsection{IMPACT OF CONTINENTALITY ON ENSO PHASES}

Another aspect of spatial variation in vegetation response can be demonstrated when the study area is divided into three subregions for comparison (Figure 4). The mean and standard deviation of NDVI for each combination of these subregions and ENSO phases provided the basis for the analysis (Figure 6). The effects of ENSO and subregion on the NDVI can be visualized by comparing the mean NDVI values between the combinations. Based on these comparisons, growing season vegetation is optimal in entire Southeastern U.S. and in all subregions during the neutral phase.

The ANOVA provides the statistical test of the effects of ENSO and subregion on NDVI, as summarized in Figure 7. The $p$-value in the figure is the probability of rejecting the null hypothesis that there is no difference between the combinations. A $p$-value less than 0.05 indicates that there is a significant difference between subregions in terms of NDVI response. The adjusted least-squares-mean (Littell et al., 1996) of NDVI is the mean value predicted with the ANOVA model for each ENSO phase and/or subregion, adjusted for spatial autocorrelation between climate divisions. 


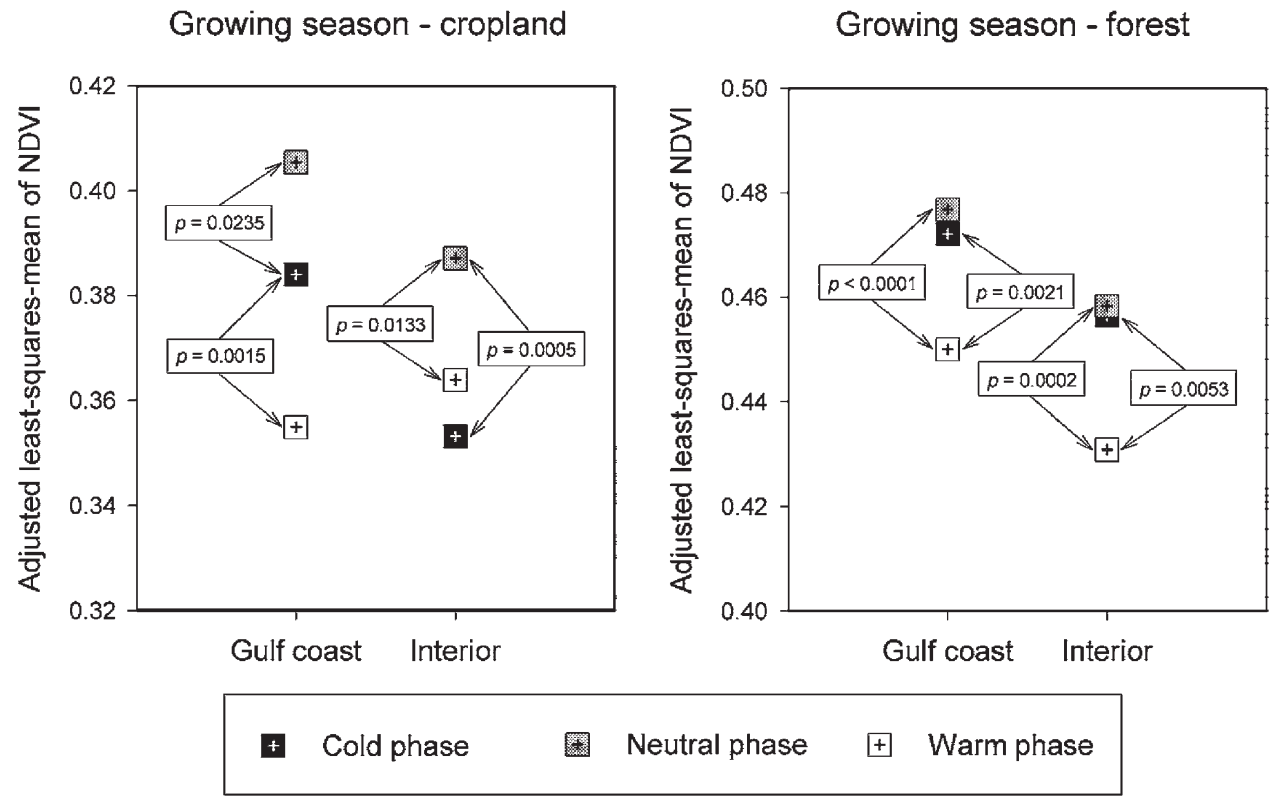

Figure 7. Comparison of ENSO phase and subregion effects on NDVI derived from the ANOVA. The boxes with $p$-values indicate the difference between two groups at $p<0.05$, suggesting that the difference between the two groups is significant.

The ANOVA results indicate that ENSO effects were significant in both the Gulf and Interior. Vegetation condition was the best during neutral SST anomalies regardless of location or type. This is attributed to the more favorable growing conditions. Along the coast, neutral and cold phase vegetation (crop and forest) was significantly better than during the warm phase, which can be attributed to the summer dryness during these periods. Vegetation response was similar both in the Interior and along the coast. That is, crops were better during neutral, relative to cold phase conditions. Forest conditions were also better during neutral and cold phases than during the warm phase.

The ANOVA results show that there is no significant interaction between ENSO and subregion for cropland $(p=0.0895)$ and for forest $(0.7347)$. In other words, there is no significant difference between Gulf coast and interior areas in terms of the ENSO impact. This suggests that variation in SSTs affects vegetation vigor in the entire Southeast, not just the Gulf coast area.

\section{Conclusions}

A vegetation response to ENSO phases was detected using AVHRR NDVI and SST information. NDVI varied between ENSO phases, type of vegetation and location (Interior vs. Gulf Coast). Based on the analyses the following conclusions can be made: 
- The neutral ENSO phase resulted in above average vegetation response, suggesting that the neutral phase provides optimal climate conditions for vegetation in the Southeastern U.S.

- The warm ENSO phase resulted in the lowest NDVI, indicating a negative effect on vegetation attributed to the cloudy-wet winters and extreme summer weather events.

- Variations in vegetation response do not strongly depend on location. ENSO has the similar influence on vegetation conditions along the Gulf Coast and in the Interior.

This study provides the most detailed investigation to date of ENSO impacts on vegetation detected with satellite sensor data in the southeastern U.S. The results of the study should promote understanding of ENSO teleconnections between the atmosphere and vegetation in the southeast U.S., and provide information to help predict ENSO effects on vegetation.

Acknowledgments - This research was supported by a NASA MTPE Grant No. OA99073, W-19, 080. We thank the two anonymous reviewers for Climate Change for their helpful comments.

\section{References}

Adams, R. M., Chen, C.-C., McCarl, B. A., and Weiher, R. F.: 1999, The Economic Consequences of ENSO Events for Agriculture, Clim. Res. 13, 165-172.

Adams, R. M., Kelly, K. J., McCarl, B. A., Legler, D. M., Obrian, J. Solow, A., and Weiher, R.: 1995, Value of Improved Long-Range Weather Information, Contemporary Economic Policy 13, 10-19.

Anyamba, A. and Eastman, J. R.: 1996, Interannual Variability of NDVI over Africa and its Relation to EL Niño/Southern Oscillation, Int. J. Remote Sensing 17, 2533-2548.

Bannari, A., Morin, D., and Bonn, F.: 1995, A Review of Vegetation Indices, Rem. Sens. Rev. 13, 95-120.

Barnett, T. P., Bengtsson, L., Arpe, K., Flugel, M., Graham, N., Latif, M., Ritchie, J., Roeckner, E., Schlese, U., Schulzweida, U., and Tyree, M.: 1994, Forecasting Global ENSO-Related Climate Anomalies, Tellus 46A, 381-497.

Barsugli, J. J., Whitaker, J. S., Loughe, A. F., Sardeshmukh, P. D., and Toth, Z.: 1999, The Effect of the 1997/98 El Niño on Individual Large-Scale Weather Events, Bull. Amer. Meteorol. Soc. 80, 1399-1408.

Batista, G. T., Shimabukuro, Y. E., and Lawrence, W. T.: 1997, The Long-Term Monitoring of Vegetation Cover in the Amazonian Region of Northern Brazil Using NOAA-AVHRR Data, Int. J. Remote Sensing 18, 3195-3210.

Benedetti, R. and Rossini, P.: 1993, On the Use of NDVI Profiles as a Tool for Agricultural Statistics: The Case Study of Wheat Yield Estimate and Forecast in Emilia Romagna, Rem. Sens. Env. 45, 311-326.

Eidenshink, J. C. and Hass, H. R.: 1992, Analyzing Vegetation Dynamics of Land Systems with Satellite Data, Geocarto International 7, 53-61. 
Eidenshink, J. C.: 1992, The 1990 Conterminous U.S. AVHRR Data Set, Photogrammetric Engineer. Remote Sens. 58, 809-813.

Eastman J. R. and Fulk, M.: 1993, Long Sequence Time Series Evaluation Using Standardized Principle Component, Photogrammetric Engineer. Remote Sens. 59, 991-996.

Goodman, S. J., McCaul, E. W. Jr., Buechler, D. E., Knupp, K., and Driscoll, K.: 2000, The 199798 El Niño Event and Related Wintertime Lightning Variations in the Southeastern United States, Geophys. Res. Lett. 27, 541-544.

Goward, S. N., Tucker, C. J., and Dye, D. G.: 1985, North American Vegetation Patterns Observed with the NOAA-7 Advanced Very High-Resolution Radiometer, Vegetatio, 64, 3-14.

Griffith, D. A.: 1996, Introduction: The Need for Spatial Statistics, in Arlinghaus, S. L., Griffith, D. A., Arlinghaus, W. C., Drake, W. D. and Nystuen J. D. (eds.), Practical Handbook of Spatial Statistics, CRC Press, Boca Raton, pp. 1-15.

Gutman, G., Csiszar, I., and Romanov, P.: 1999, Using NOAA/AVHRR Products to Monitor EL Niño Impacts: Focus on Indonesia in 1997-98, Bull. American Meteorol. Soc. 81, 1189-1205.

Hansen, J. W., Hodges, A. W., and Jones, J. W.: 1998, ENSO Influence on Agriculture in the Southeastern United States, J. Climate 11, 404-411.

Holben, B. N.: 1986, Characteristics of Maximum-Value Composite Images from Temporal AVHRR Data, Int. J. Remote Sensing 7, 1417-1434.

Holben, B. N., Kaufman, Y. J., and Kendall, J. D.: 1990, NOAA-11 AVHRR Visible and Near-IR Inflight Calibration, Int. J. Remote Sensing 11, 1511-1519.

Justice, C. O., Townshend, J. R. G., Holben, B. N., and Tucker, C. J.: 1985, Analysis of the Phenology of Global Vegetation Using Meteorological Satellite Data, Int. J. Remote Sensing 6, 1271-1318.

Katz, R. W., Parlange, M. B., and Tebaldi, C.: 2003, Stochastic Modeling of the Effects of LargeScale circulation on Daily Weather in the Southeastern U.S., Clim. Change 60, 189-216.

Kiladis, G. N. and Diaz, H. F.: 1989, Global Climate Extremes Associated with Extremes of the Southern Oscillation, J. Climate, 2, 1069-1090.

Kogan, F. N.: 2000, Satellite-Observed Sensitivity of World Land Ecosystems to El Niño/La Niña, Rem. Sens. Env. 74, 445-462.

Kuehl, R. O.: 2000, Design of Experiments: Statistical Principles of Research Design and Analysis, 2nd edn., Duxbury/Thomson Learning, Pacific Grove, CA, 666 pp.

Legendre, P.: 1993, Spatial Autocorrelation: Trouble or New Paradigm?, Ecology 74, 1659-1673.

Li, Z. and Kafatos, M.: 2000, Interannual Variability of Vegetation in the United States and its Relation to El Niño/Southern Oscillation, Rem. Sens. Env. 71, 239-247.

Littell, R. C., Milliken, G. A., Stroup, W. W., and Wolfinger, R. D.: 1996, SAS System for Mixed Models, SAS Institute Inc., Cary, NC, 633 pp.

Liu, W. T. and Negrón Juárez, R. I.: 2001, ENSO Drought Onset Prediction in Northeast Brazil Using NDVI, Int. J. Remote Sensing 17, 3483-3501.

Loveland, T. R., Merchant, J. W., Ohlen, D. O., and Brown, J. F.: 1991, Development of a LandCover Characteristics Database for the Conterminous United States, Photogrammetric Engineer. Remote Sens. 57, 1453-1463.

McCabe G. J. and Denttinger, M. D.: 1999, Decadal Variations in the Strength of ENSO Teleconnections with Precipitation in the Western United States, Int. J. Clim. 19, 1399-1410.

Mennis J.: 2001, Exploring Relationships between ENSO and Vegetation Vigor in the SouthEast U.S.A. Using AVHRR Data, Int. J. Remote Sensing 22, 3077-3092.

Moulin, S. A., Bondeau, A., and Delecolle, R.: 1998, Combining Agricultural Crop Models and Satellite Observations: From Field to Regional Scales, Int. J. Remote Sensing 19, 1021-1036. 
NOAA/USDA, Joint Agricultural Weather Facility: 1989-2000, Weekly Weather and Crop Bulletin, Vols. 77-87, NOAA/NWS/NCEP/CPC, Camp Springs, Maryland, published weekly.

Rajagopalan, B., Cook, E., U. Lall, and Ray, B. K.: 2000, Spatiotemporal Variability of ENSO and SST Teleconnections to Summer Drought over the United States during the Twentieth Century, J. Climate 13, 4244-4255.

Ropelewski, C. F. and Halpert, M. S.: 1986, North American Precipitation and Temperature Patterns Associated with EL Niño/Southern Oscillation (ENSO), Mon. Wea. Rev. 114, 2352-2362.

Sellers, P. J., 1985: Canopy Reflectance, Photosynthesis and Transpiration, Int. J. Remote Sensing 6, 1335-1372.

Trenberth, K. E.: 1997, The Definition of El Niño, Bull. Amer. Meteorol. Soc. 78, 2771-2777.

Trenberth, K. E. and Hoar T.: 1996, The 1990-1995 El Niño-Southern Oscillation Event: Longest on Record, Geophys. Res. Lett. 23, 57-60.

Tucker, C. J. Dregne, H. E., and Newcomb, W. W.: 1991, Expansion and Contraction of the Sahara Desert from 1980 to 1990, Science 253, 299-301.

Tucker, C. J. and Sellers, P. J.: 1986, Satellite Remote Sensing of Primary Production, Int. J. Remote Sensing 7, 1396-1416.

Unganai, L. S. and Kogan, F. N.: 1998, Drought Monitoring and Corn Yield Estimation in Southern Africa from AVHRR Data, Rem. Sens. Env. 63, 219-232. 